\title{
Structural Behaviour of Prefabricated Pad Footing Foundation with Cold-Formed Steel Lipped Channel Sections
}

\author{
Mahmood M. T. ${ }^{1}$, Nur Adilah M. I. ${ }^{2 a}$, Koo T. C. ${ }^{2 b}$ and Shek P. N. ${ }^{3}$
}

\begin{abstract}
Pad footing foundations are traditionally made of concrete reinforced by high tensile steel bars moulded by timber formwork. This type of fabrication has three main disadvantages, which are large deviation of intended geometry due to weak structural integrity of used timber formworks, wastage of timber material as temporary timber formwork does not contribute to the strength of pad footing and as to be disposed after a certain number of usage, and longer construction time due to the need to remove the timber formwork after the concrete has hardened. Due to these disadvantages, the traditional method of constructing pad footing can cause an increase in construction cost and time, uncertainty in the quality of the final product and also environmental issues from the disposal of used timber formwork. To overcome the existing flaws of pad footing construction, the concept of pre-fabrication construction of pad footing foundation has been introduced using cold-formed steel lipped channel sections to replace timber as permanent formwork, and to replace high tensile steel bars as reinforcement in the pad footing foundation. However, such practice of using cold-formed steels in pre-fabricated pad footing foundation is still uncommon and no design guide has been established yet. This thesis investigates the moment and shear resistances of such pre-fabricated pad footing foundation designed to BS EN 1992-1. A total of 6 specimens were tested, where the size is designated as $1.0 \mathrm{~m}$ width $\mathrm{x} 1.0 \mathrm{~m}$ long $\mathrm{x} 150 \mathrm{~mm}$ thick footings. The experimental and theoretical calculation was on good agreement and the use of cold-formed steel increased the structural resistance of the footing due to composite effects. As a result, the proposed pre-fabricated pad footing foundation using cold-formed steel lipped channel sections is proved to be feasible in actual.
\end{abstract}

Index Terms - fad footing, fabrication, cool-formed steel, formwork, structural resistance.

\section{INTRODUCTION}

Industrialized building system (IBS) defined as the process of construction that applied techniques, products, components or building system in which components are manufactured in a restricted environment whether it involved with prefabricated components and on-site installation [7]. Quality, speed of

Mahmood M. Tahir and Shek P.N. are with UTM Construction Research Centre (UTM CRC), ISIIC, Faculty of Civil Engineering, Universiti Teknologi Malaysia, 81310 UTM, Johor, Malaysia

Nur Adilah M. I. and Koo T.C. are Graduate Student with the Faculty of Civil Engineering, University Teknologi Malaysia, 81310 UTM, Johor, Malaysia

Shek P.N. is with the UTM Construction Research Centre (UTM CRC), ISIIC, Faculty of Civil Engineering, Universiti Teknologi Malaysia, 81310 UTM, Johor, Malaysia. construction and cost saving are the main factors emphases given in the building construction.

Steel construction, there are primarily two types of structural members which namely as hot-rolled steel shape and cold formed steel shapes. Cold formed steel (CSF) is a thin sheet steel which has been used extensively in building industry and range from the purlins to roof sheeting and floor decking. It offers many other advantages, including lightness, high strength and stiffness, mass production, fast and easy installation and economy in transportation and handling [1]. Cold formed steel members is formed within room temperature and made from structural quality sheet steel then it formed into shape, either through press-braking blanks sheared from sheets or coils or more commonly by roll forming the steel through a series of dies. The steel used in CFS sections is relatively thin, typically $1.0-4.0 \mathrm{~mm}$ and it is galvanized for corrosion protection.

The application of CFS is widely used in many sectors of construction, for instance mezzanine floors, industrial buildings, commercial buildings, hotels and residential sectors. The main forms of construction include load-bearing frames and infill walls of steel or concrete framed buildings. There are many methods of construction using CFS, such that, light steel framing, stick built construction, panel construction, modular construction, platform and balloon construction, infill wall construction and balconies. Steel constructions have achieved high demand in several of the sector where the main benefits include high speed of construction, higher level of quality, reliability and longevity. Steel quality also assured high strength, long life, adaptable.

Why cold-formed steel as pad footing?

The conventional pad footing was constructed using plywood as formwork and rebar, therefore both materials, increasing the use of workmanship in construction site and increasing the wastage which would contribute in increasing of overall construction cost. As nowadays, most of construction site encounters main problems of abandoned of wastage where some of the plywood cannot be used anymore. Foremost, the conventional method of construction also increases the duration of the project.

The use of pre-fabrication concept for the construction of pad footing structures is rarely been done, especially in a pad footing system, thus, there is a need to encourage the local builders and designers to implement this concept in order to speed up the construction time, reduce workers, reduce material 
usage and provides a better quality of the construction. The implementation of pre-fabricated pad footing is expected to enhance the global competitiveness of local builders and designers while the dependency of foreign labors could be reduced. In this research, the performance of the prefabricated pad footing system using cold formed steel lipped channel section is investigating. The objectives of this study are:

1. To study the structural behavior of CFS section in pad footing system by carried out experimental tests.

2. To validate the capacity of the CFS section in pad footing system by comparing the experimental result with theoretical prediction.

3. To compare the economical aspect of CFS in pad footing system with conventional pad footing throughout the steel area required.

\section{Scope of Study}

In experimental works, there are six (6) full-specimens of square footing $(1 \mathrm{~m} \times 1 \mathrm{~m})$ with different configuration. All samples subjected to axial compression test. From the experimental test, the structural behavior and failure mechanism of prefabricated pad footing using CFS lipped channel section were recorded. The capacity of pad footing from the experimental test was validated with theoretical prediction and study on economical aspect of CFS is determined throughout steel area required by comparing with conventional pad footing.

\section{LITERATURE REVIEW}

Industrialized building system (IBS) defined as the process of construction that applied techniques, products, components or building system in which components are manufactured in a restricted environment whether it involved with prefabricated components and on-site installation [7]. The use of prefabricated system has known to increase the strength of the structure, shear capacity and the bending moment of the structural members. The steel frame system is one of the types for pre-fabricated building materials and it is most compatible due to steel is light in weight, strong and structurally stable and also environmentally friendly.

Currently the pre-fabricated system in construction is being popularized under government effort by introducing the comprehensive national Industrialized Building System (IBS) by the Construction Industry Development Board Malaysia (CIDB). Various efforts have been made to benefit the pre-fabricate construction in Malaysia. Quality, speed of construction and cost saving are the main factors emphases given in the building construction. A building system for the fully pre-fabricated construction method can be classified into two main categories which are on-site pre-fabricated and the off-site pre-fabricated [8]. Selangor was the first state in Malaysia that would advance in the concept of pre-fabricated affordable housing to fulfill the demand of homes needed by the society from the low - income group [7].

Steel construction, there are primarily two types of structural members which namely as hot-rolled steel shape and cold formed steel shapes. This thesis more concentrated on cold formed steel (CFS) as main material to construct and design the pad footing. Cold formed steel members is formed within room temperature and made from structural quality sheet steel then it formed into shape, either through press-braking blanks sheared from sheets or coils or more commonly by roll forming the steel through a series of dies. The steel used in CFS sections is relatively thin, typically $1.0-4.0 \mathrm{~mm}$ and it is galvanized for corrosion protection [1].

Cold formed steel (CFS) members depend on shape rather than thickness to support the loading and normally the thickness of the CFS members are small compared to their width. Therefore, when steel member subjected to axial compressive stresses, the thin compression member tends to buckle before it reaches yield strength. As the cross section of an element fails, the member capacity is reached. Consequently, local buckling becomes a limit state for strength of steel shapes subjected to compressive stress and the designing of compression members focused on the calculation of its buckling resistance. Previous study of composite structure was focus on profile steel sheeting where local buckling may occur when the profiled steel sheeting is subjected to axial loads. Composite structure has higher stress at which elastic buckling occurs compared with the non-composite structure because of the intimate contact of steel and concrete cause restraint with the plate which delays the formation of buckles [4].

In the concept of the composite structure of composite profiled beams and fully braced box section which constructed as formwork before pouring the concrete to form a composite profiled beam. The result showed that an increase in flexural strength and more ductile than reinforced concrete beam as the reduction of $40 \%$ in deflection and increasing of span/depth ratio as much as $20 \%$. This proved that this structure may undergo local buckling as there were increases in the span / depth ratio [5]. The used profiled sheet as formwork to form a composite profile beams showed that the composite beam is unlike the standard forms of buckling of thin plate element because of concrete restricted to form outwards and the result proved that increasing of the width of the plate about $70 \%$ as this buckling permit [6].

Wong [3] proposed the composite structure of pad footing constructed using cold formed steel lipped channel section as permanent formwork and BRC as reinforcement. The implementation of prefabricated pad footing was using framing system approach for the formwork. The used of CFS lipped channel section as permanent formwork showed an increment in the strength of the pad footing range from $48 \%$ to $124 \%$. The conclusion of this research shown that data of the actual strength of the pad were $97.7 \%$ of the calculation derived values.

\section{Methodology}

The main objective of the research is to study the structural behavior and failure mechanism of prefabricated pad footing using CFS. In addition, the ultimate load capacity of pad footing in the experiment was compared with theoretical prediction. This research methodology consisted of 3 key activities: prefabricated of pad footing preparation, material test on ready 
mix concrete samples and coupon steel of CFS and axial compression experiment.

\section{Fabrication of Pad Footing Preparation}

Prefabricated pad footings were fabricated using CFS lipped channel section galvanized with high tensile steel G500, which is minimum yield strength is $500 \mathrm{MPa}$. The dimension of CFS is $150 \mathrm{~mm} \times 65 \mathrm{~mm} \times 1.6 \mathrm{~mm}$ were used to construct the frame of pad footing based on the proposed size of pad footing to form a permanent formwork and the internal CFS were arranged according to the proposed orientation of this study as shown in Fig ( $a$ and $b$ ). There are total six samples of prefabricated pad footing were prepared and each sample divided into three cases as shown in Table 1. Internal CFS were arranged evenly based the size of footing and the dimension of CFS.

TABLE I: SUMMARIZE DIMENSION OF PAD FOOTING

\begin{tabular}{ccccc}
\hline Cases & $\begin{array}{c}\text { Width } \\
(\mathbf{m m})\end{array}$ & $\begin{array}{c}\text { Breadth } \\
(\mathbf{m m})\end{array}$ & $\begin{array}{c}\text { Height } \\
\text { of the } \\
\text { pad } \\
(\mathbf{m m})\end{array}$ & $\begin{array}{c}\text { Configuration } \\
\text { of internal } \\
\text { CFS }\end{array}$ \\
\hline Case 1 & 1000 & 1000 & 150 & XX-direction \\
\hline Case 2 & 1000 & 1000 & 150 & YY-direction \\
\hline Case 3 & 1000 & 1750 & 150 & YY-direction \\
\hline
\end{tabular}

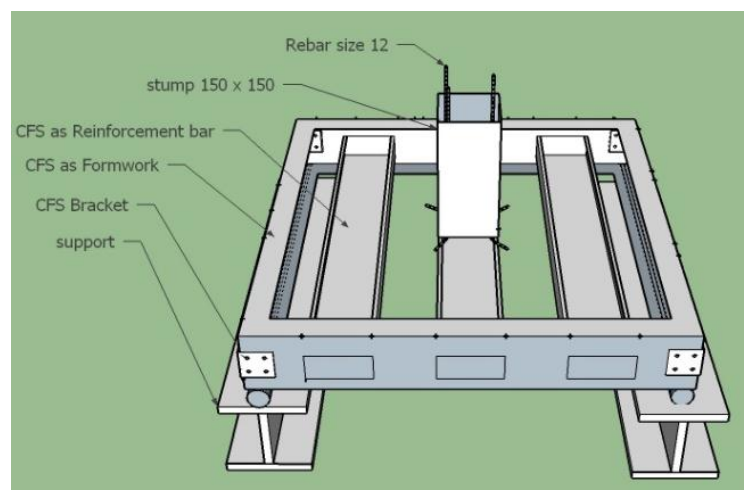

Fig. 1 (a) Arrangement of internal CFS for case 1

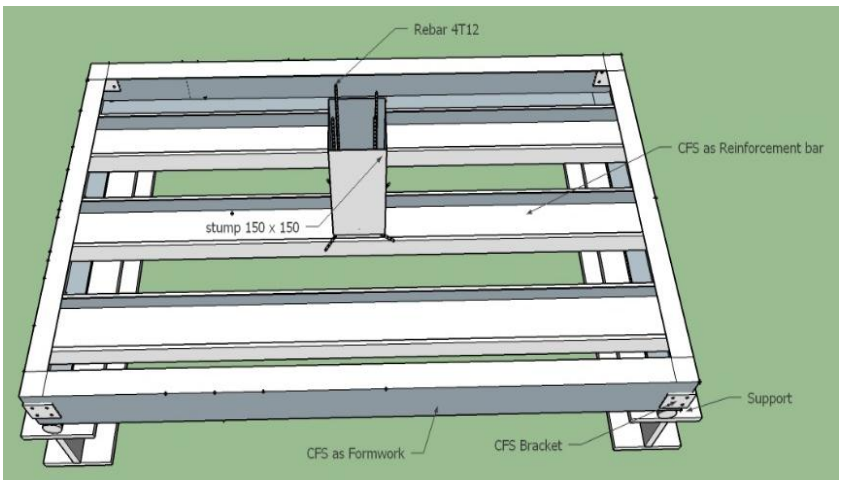

Fig. 1 (b) Arrangement of internal CFS for case 2.

Fig. 1 Proposed prefabricated pad footing using CFS

\section{Material Characteristic Test}

Cube Compression Test. Compression test is used to measure the compression strength, $\mathrm{F}_{\mathrm{cu}}$ of a concrete. Three cubes of size $150 \mathrm{~mm}$ were prepared using excess concrete after casting process was done and the cube was cured for 28 days, and placed in the TONIPAC 300 Testing Machine. The load was applied at a constant rate of $0.2 \mathrm{kN} / \mathrm{m}^{2} / \mathrm{s}$ until the concrete cube failed. The average maximum load of three samples was recorded as compressive strength, $\mathrm{F}_{\mathrm{cu}}$.

Tensile Test. Tensile test is used to predict the behavior of material under forms of loading and it is measured during development of new materials and process so that different materials and processes can be compared. The strength of materials is measured in term of stress which cause appreciable plastic deformation or maximum stress that a material can withstand. The CFS lipped channel section were cut into 6 coupon shape and each sample is labeled, then placed in the DARTEC Universal Testing Machine to comply BS EN 10002-1:2001 to determine the yield strength and ductility of the materials used. The stress was applied until the coupon steel can no longer received any stress. The average maximum stress of six samples was recorded as yield strength, $\mathrm{F}_{\mathrm{yk}}$.

Axial Compression Test. The axial compression test is used to measure the ultimate capacity of prefabricated pad footing. There are total six full scale of samples were prepared according to specification where the samples was divided equally into three cases. The test was conducted using the DARTEC Test Rig with the tested sample laid on roller I-beam. I-beam is used to elevate the samples above the ground to allow for testing of shearing. This machine also will read load and displacement concurrently at one second interval. After desired concrete strength achieves, the sample was securely placed in the test rig with the measurement system. The data deflection software in the computer was checked to ensure all channel connected to the instrument, the test was started and the load was applied constantly until the pad footing failed. The result of the load, deflection and failure mode was recorded. The graph of load against displacement was plotted.

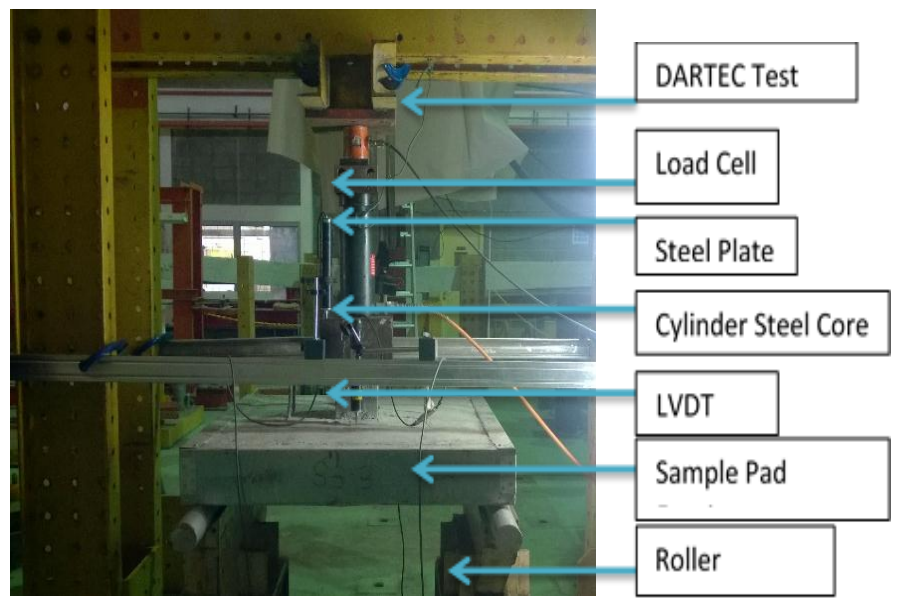

Fig. 2 DARTEC Test Rig setup equipment for axial compression test using I-beam

\section{RESULTS AND DISCUSSION}

The results of material properties of ready mix concrete and CSF steel and experimental test on a prefabricated pad footing using CFS were obtained. The material properties were used to define the readily mix concrete material and CFS steel yield 
strength, and the properties were inserted into the theoretical calculation to get the actual theoretical prediction for pad footing. The failure mode of pad footing was observed to determine the type of failures occurs. The results of the axial compression test of prefabricated pad footing were compared with theoretical calculation. The economical aspect of CFS was compared with conventional pad footing throughout the steel area required.

\section{Axial Compression Test}

Failure Mode of Pad Footing. All samples undergo the process of gradually increment of concentrated load applied through cylinder steel core from the DARTEC Test Rig and transferred between the steel plate located between the stump and cylinder steel core. Based on the observation in case one, all samples showed no effect in the early stage of loading. When the load is gradually increased the crack start to occur, the first crack occurred at load $44.9 \mathrm{kN}, 90 \mathrm{kN}$ and $54 \mathrm{kN}$ with a displacement of $0.59 \mathrm{~mm}, 4.38 \mathrm{~mm}$ and $0.15 \mathrm{~mm}$. When the load increases further a lot of crack occurs especially at the bottom of pad footing, top of the footing and the bracket began to lose. A wide line of crack Y-direction appears and cause the pad to fail received any load increment. When the pad footings can no longer receive any load and load value start to decrease gradually, the experiment was stopped. The pad footing was filed in flexural due to a crack occur at the column face.

In case three, throughout the observation, the samples have same failure modes as in case one which is flexural failure. In the beginning of the experiment, all samples showed no effect in the early stage of loading. When the applied load was gradually increased the crack start to occur, the first crack occurred at load $122 \mathrm{kN}, 132 \mathrm{kN}$ and $163 \mathrm{kN}$ with a displacement of $5.98 \mathrm{~mm}$, $2.23 \mathrm{~mm}$ and $9.41 \mathrm{~mm}$. When the load increases further a lot of crack occurs especially at the bottom and top of pad footing. The bracket was still in good conditioned. When the pads can no longer receive any load and load value start to decrease gradually, the experiment was stopped. The failure mechanism of rectangular pad footing due to a large crack occurs in the column face in $\mathrm{x}$-direction which known as flexural failure. Figure 1 showed the flexural failure in case one.

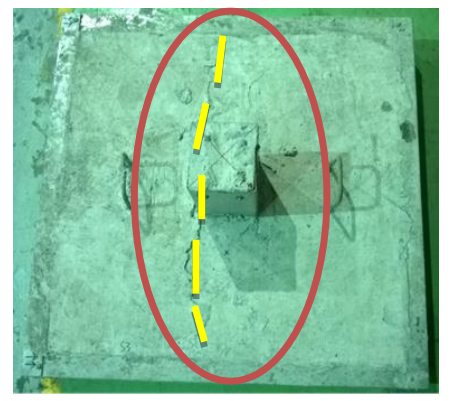

Fig. 3 (a) Vertical line of crack at the column face for case 1

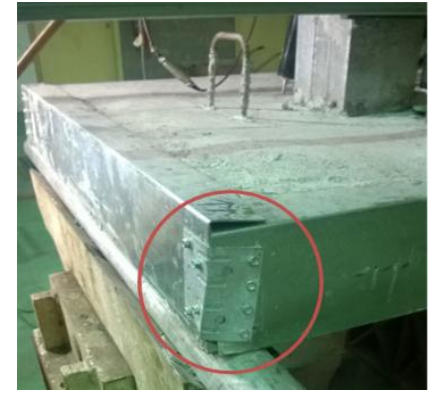

Fig. 3 (b) Bracket torn off

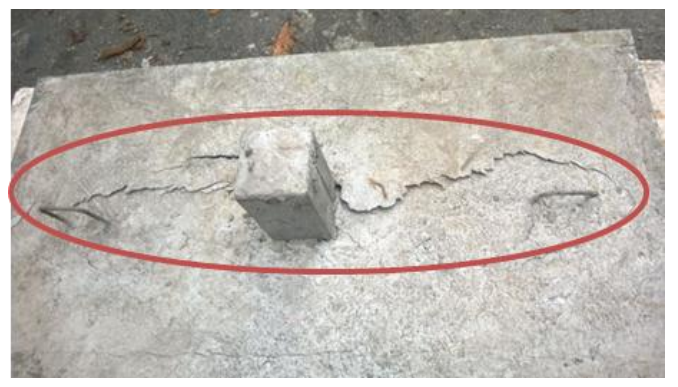

Fig. 3 (c) Horizontal line cracks in the column face for case 3

Fig. 3 Flexural failure was observed in pad footing

In case two, based on the observation, all samples proved to have normal shear failures because of the test result showed similar results with theoretical prediction. The failure mechanism for case two occurs at the bottom of pad footing where diagonal crack patterns develop at distance of $1 \mathrm{~d}$ from column face. During the experiment, all samples showed no effect in the early stage of loading. When the applied load was gradually increased the crack start to occur, especially at the bottom of pad footings, the first crack occurred at bottom of pad at load $155 \mathrm{kN}, 139.3 \mathrm{kN}$ and $80.8 \mathrm{kN}$ with a displacement of $4.68 \mathrm{~mm}, 3.83 \mathrm{~mm}$ and $1.04 \mathrm{~mm}$. Further increase in applied load resulting in significant vertical displacement and reduction in applied load. When the pads can no longer receive any load and load value started to decrease gradually, the experiment was stopped. The pad footing also failed due to a line crack $1 d$ from the column face in $\mathrm{x}$-direction.

Ultimate Load Capacity. Ultimate load capacity refers to the maximum load or the failure load of pad footing can withstand. Table 2 showed summarize of maximum load of pad footing with a corresponding vertical displacement of each tested sample. From table 2, it shows that all samples show good result of maximum loads where all samples able to cater soil bearing capacity of $100 \mathrm{kN} / \mathrm{m}^{3}$. Although, there is a slightly different result in case 1 and case 2, this might due to orientation of internal CFS. In case 2, it seems the orientation of internal CFS contributes to the strength of pad footing compared to the case 1. Therefore, the ultimate load capacity for case 2 is higher than in case 1 .

Theoretical Validation. It is essential to make comparison between theoretical prediction and experimental test in order to have a better understanding of the structural behavior of pad footing using CFS. From table 2, it showed that experimental 
test in all cases give an excellent result of load capacity of pad footing. Thus, the experimental test proved the theoretical calculation as all the experimental test value is higher than theoretical predictions.

In case 1 , Although the orientation of internal CFS seem does not contribute much to the structural performance of pad footing, but the experimental test result shows an increment of loading compared to theoretical prediction where the maximum load in experimental is $109.8 \mathrm{kN}, 121.3 \mathrm{kN}$ and $150.1 \mathrm{kN}$ and the ratio of experimental over the theoretical range from 1.25 to 1.71. This result also proved the theoretical prediction where all samples failed in flexural.

In case 2, the internal CFS successfully contribute to the overall structural behavior of pad footing where the theoretical prediction is expected to fail at load $182.29 \mathrm{kN}$, while The experimental test result showed an increment of load compared to theoretical with a load of $216.2 \mathrm{kN}, 189.6 \mathrm{kN}$ and $200.4 \mathrm{kN}$ and a ratio of $1.19,1.04$ and 1.10 . The experimental test proved the theoretical prediction and all samples fail in normal shear. TABLE II: EXPERIMENTAL TEST RESULT AND THEORETICAL PREDICTION WITH CORRESPONDING DISPLACEMENT AND INITIAL STIFFNESS.

\begin{tabular}{lcccc}
\hline Cases & Sample & $\begin{array}{c}\text { Exp. test } \\
(\mathbf{k N})\end{array}$ & $\begin{array}{c}\text { Theo. } \\
(\mathbf{k N})\end{array}$ & $\begin{array}{c}\text { Exp/Theo } \\
\text { ratio }\end{array}$ \\
\hline Case 1 & S1-1 & 109.8 & & 1.25 \\
& S1-2 & 121.3 & 87.87 & 1.38 \\
& S1-3 & 150.1 & & 1.71 \\
\hline Case 2 & S2-1 & 216.2 & & 1.19 \\
& S2-2 & 189.6 & 182.29 & 1.04 \\
& S2-3 & 200.4 & & 1.10 \\
\hline Case 3 & S3-1 & 185.2 & & 1.43 \\
& S3-2 & 172.43 & 129.80 & 1.33 \\
& S3-3 & 167.1 & & 1.29 \\
\hline
\end{tabular}

\section{Economical Aspect of CFS}

Steel Area Required. The use of CFS as reinforcement bar and formwork give lots of benefits compared using conventional pad footing. This is because Conventional method of constructing the pad footing required a lot of workmanship and resulting in low quality of the pad footing. Thus, there is a need to study on the economical aspect of CFS by comparing with conventional pad footing throughout steel area required which using reinforcement bar size $12 \mathrm{~mm}$ diameter.

Overall, conventional method seems to have a smaller steel area required compared to CFS. This is because in conventional pad footing, steel area required only take account the reinforcement bar to support the footing in tension and not the formwork. Formwork does not contribute to the strength of pad footing. Therefore, after concrete achieved its strength, the formwork will pull off and will not be used anymore. Mostly the abundance of unused formwork will increase the wastage and contribute to the additional construction cost. Thus, the conventional method is not economic.

From the graph below, it showed that CFS has larger steel area required. This is because CFS lipped channel section is used as reinforcing bar and also permanent formwork. The use of CFS as permanent formwork contributes to the overall structural behavior of the pad footing compared to using conventional pad footing. Therefore, the steel area of formwork would be including in overall steel area required by the pad footing when using fully CFS in pad footing. Besides, CFS lipped channel section can reduced the wastage such that there is no need to use plywood as formwork because CFS can also be use as permanent formwork. Thus, the additional cost of construction due to the wastage can be reduced.

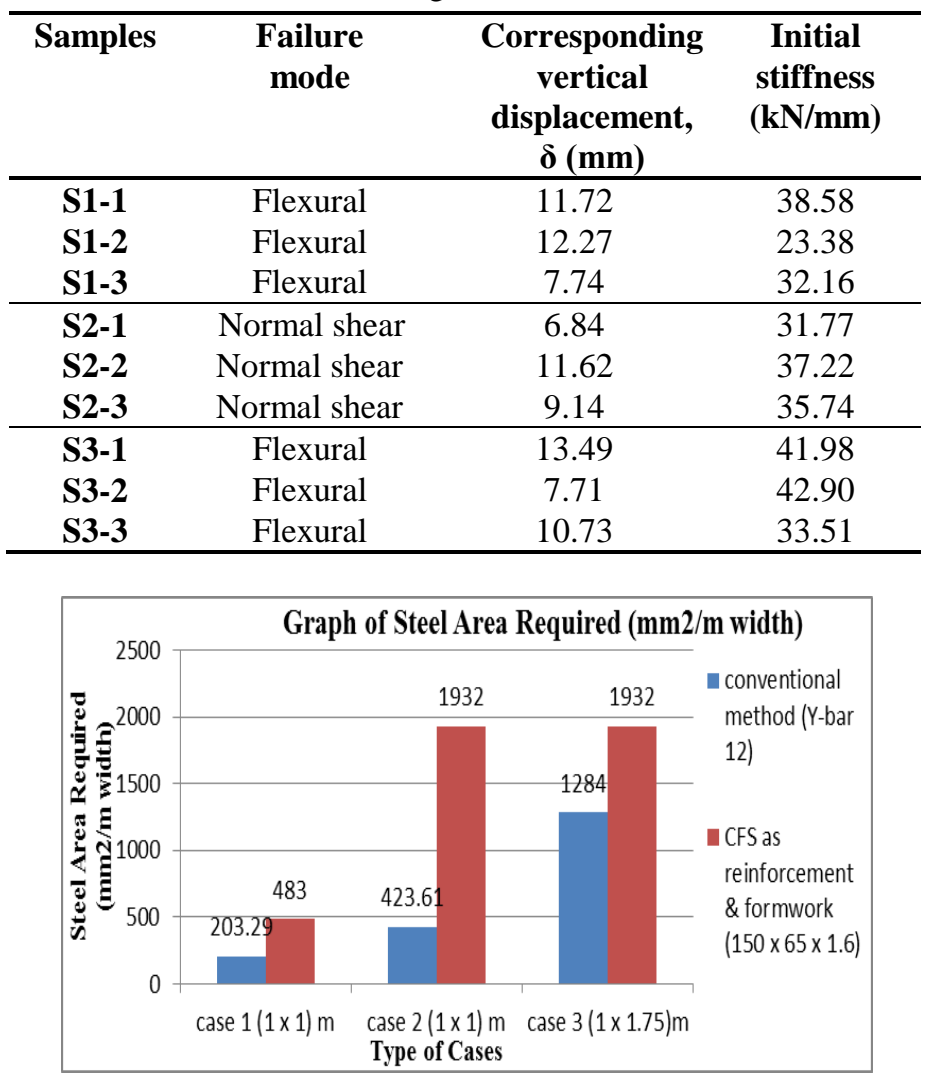

Fig. 5 Graphs of the steel area required for conventional method and using CFS

\section{CONCLUSION}

This research presents the structural behavior of CFS section in pad footing throughout the experimental test by validate the capacity of the CFS section with theoretical prediction and comparing the economical aspect of pad footing using CFS.

1. From the experiment of the axial compression test, the structural behavior of pad footing using CFS had been evaluated and showed excellent results of structural behavior when using CFS as reinforcement bar and permanent formwork.

2. Based on the experiment works, the capacity of pad footing for each case proved the theoretical prediction with a ratio range from 1.04 to 1.71 where all cases shown increment in ultimate load capacity. The maximum load in case one is $109.8 \mathrm{kN}, 121.3 \mathrm{kN}$, $150.1 \mathrm{kN}$ while for case 2 is $216.2 \mathrm{kN}, 189.6 \mathrm{kN}$ and $200.4 \mathrm{kN}$.

3. Although the steel area required for CFS is higher 
compared with conventional pad footing, but the used of CFS in pad footing system is more economical due to less wastage occurs as the formwork is replaced with CFS which act as permanent formwork

\section{ACKNOWLEDGMENT}

The work reported in this study was graciously supported by Translational Research Grant (TRG) under Universiti Teknologi Malaysia with grant number R.J130000.7809.4L858 and chargeline number A.J091201.5541.07121 (UMUM-PERUNDINGAN CTMC). The authors remain indebted for the support given by them.

\section{REFERENCES}

[1] Yu, C. and Schafer, B.W., "Distortional buckling of cold-formed steel members in bending,", 2005.

[2] Badir, Y.F., Kadir, M.A. and Hashim, A.H., "Industrialized building systems construction in Malaysia," Journal of Architectural Engineering, vol. 8, no. 1, pp.19-23, 2002. https://doi.org/10.1061/(ASCE)1076-0431(2002)8:1(19)

[3] Wong, K.L., "Structural behaviour of pre-fabricated composite pad footing foundation using cold-formed steel lipped channel sections," Ph.D. dissertation, Universiti Teknologi Malaysia, 2010.

[4] Winter, G., "Strength of thin steel compression flanges," Transactions of the American Society of Civil Engineers, vol. 112, no. 1, pp.527-554, 1947.

[5] Oehlers, D.J., "Composite profiled beams," Journal of Structural Engineering, vol. 119, no. 4, pp.1085-1100, 1993. https://doi.org/10.1061/(ASCE)0733-9445(1993)119:4(1085)

[6] Oehlers, D.J., Wright, H.D. and Burnet, M.J., "Flexural strength of profiled beams," Journal of Structural Engineering, vol. 120, no. 2, pp.378-393, 1994. https://doi.org/10.1061/(ASCE)0733-9445(1994)120:2(378)

[7] Mohamad, D., Ramli, M.Z., Danuri, H.N. and Sapuan, W.K., "Demand of the industrialized building system (IBS) implementation in Malaysian government projects," 2016.

[8] Badir, Y., "Theory of classification: its application and Badir-Razali building Systems classification," Journal of Institute Engineer, 1998.

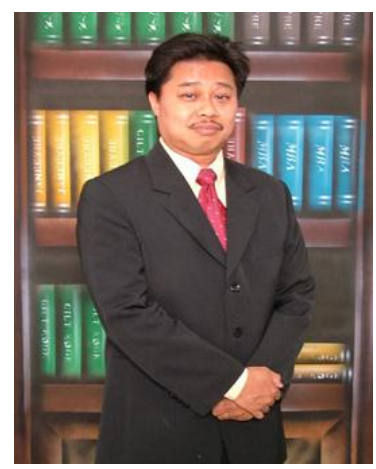

Prof Ir. Dr Mahmood joined UTM in May 1985 as Assistant Lecturer "A" after completing his first degree from University of Iowa, USA. He taught diploma students from May 1985 to 1988 before pursuing his Master degree at University of Nebraska Lincoln, USA. After completing his master degree (M.Sc) in Structure Engineering, he continued to serve FKA, UTM from 1989 to 1993. During that period he taught degree students on theory of structure and structure mechanics subjects. In 1990 to 1991 he has been granted permission by UTM to carry out practical training as full-time design and practicing engineer with Ling and Wong Consultant Private Limited in Johor Bahru, Johor. He continued his study for Ph.D in Jan 1994 at University of Warwick, U.K and managed to complete his study in May 1997. He continued his service with FKA UTM at Steel Technology Centre as fellow of the center. In 1999, he managed to get his professional engineer status from Board of Engineers Malaysia. In 2000, he has been appointed as Associate Professor and Director of Steel Technology Centre. In 2008, he has been appointed as full professor. During his involvement in research and publication for the last 20 years, he has published 50 indexed journals and 78 conference papers. He involved in research exhibition at Invention and New Product Exposition (INPEX) 2004, May 12-15, 2004. Pittsburgh, PA USA and managed to won silver medal. He also involved in research exhibition at Innovative and Research Product, $34^{\text {th }}$ International Exhibition of Invention, New Techniques and Product of Geneva 2006 and Malaysia Technology Expo 2006, 23 - 25 Feb 2006, PWTC, K. Lumpur. At both exhibitions, he managed to secure gold medal. His main areas of research are steel structures, composite structures, and concrete structures. $\mathrm{He}$ also is registered as member of Institute Engineer Malaysia (MIEM). At present, he is a director of Institute for Smart Infrastructure and Innovative Construction. 